\title{
Parietal lobe deficit in the mentally retarded
}

\author{
P. E. SYLVESTER
}

From St. Lawrence's Hospital, Caterham, Surrey

The parietal lobes are defined approximately as an irregular pentagon bounded anteriorly by the central sulcus, superiorly by the supero-medial margin of the hemisphere between the central sulcus and the parieto-occipital sulcus, posteriorly by an imaginary line taken from the supero-medial margin at the point where it is cut by the parieto-occipital sulcus and the pre-occipital notch, and inferiorly by the posterior ramus of the lateral sulcus and a line drawn backwards to the posterior boundary from the point where the ramus turns upwards (Gray, 1958).

Physiologically, the lobes have been likened by Ritchie Russell (1961) to storehouses in which the recognition and elaboration of all types of sensory experiences in motor responses are organized. Physiological and clinical appraisal of parietal lobe function in man has been fully appraised by Critchley (1953).

The corpus callosum provides the neopallial commissural system by which symmetrical parts of the hemispheres are connected. Those fibres which connect the parietal lobes traverse the posterior third of the callosal body. Bailey and Von Bonin (1951) state that there is very little direct information about the origin and distribution of callosal fibres, but Riley (1960) believes their origin to be from small pyramidal cells in cortical layers III to V. Likewise there is uncertainty whether the fibres are axons or collaterals. Some fibres are myelinated and others non-myelinated; according to Tomasch (1954), nonmyelinated fibres constitute $40-50 \%$ of the total. Often the superior callosal surface is irregular, and McRae and Castorina (1963) estimated that irregularity occurs in $70 \%$ of brains and that this is most often a localized depression in the posterior part of the body.

Physiologically, the animal experiments by Myers (1959) and Ettlinger and Morton (1963) revealed that learned tasks of one hemisphere were transferred to the opposite hemisphere with an intact callosum, but these feats could not be accomplished after division of the callosum.

Measurements of the lobes of the brains of eight mentally defective patients and estimation of the thickness of the posterior part of the bodies of the corpora callosa have been made. This paper reports the findings, compares them with similar figures from normal brains, and correlates the measurements.

\section{MATERIAL}

An analysis of 84 brains from mentally subnormal patients revealed that in eight instances $(9.5 \%)$ there was a localized thinness of the body of the corpus callosum in its posterior part, just anterior to the splenium. The patients (five males and three females) were aged from 22 to 63 years. Their mental grading was one idiot and seven imbeciles, and their infirmities dated from either infancy or early childhood. All the patients were ambulant and free from spasticity. Seven were right handed and one was ambidextrous. There were five epileptics.

Significance is attached to the fact that the eight brain? here studied were picked out from a large sample of brains because they all had in common thinning o $\vec{D}$ the posterior callosal body. Measurements on parietaf lobes had been made at the time of routine brain dis- $\rightarrow$ section by one observer some time earlier. Thus the cerebral measurements have been done 'blind' and not tailored to fit the callosal size. The weights of the brains. $\vec{\oplus}$ ranged from $929 \mathrm{~g}$. to $1,382 \mathrm{~g}$. (mean $=1,186 \mathrm{~g}$.).

\section{METHODS}

All measurements and observations were made on tissues fixed in neutralized formalin in normal saline, the brain having been inverted and suspended from a thread under the basilar artery in the fixative.

The parietal lobe, for the purpose of this study, was similar to the previous anatomical definition except for its inferior margin, which was taken as an imaginary line from the pre-occipital notch to the junction of the central sulcus, or its downward projection, with the lateral sulcus; thus the supero-posterior part of the temporal lobe was included in the measurement. Measurements were made with a pair of dividers. Two measurements on the frontal lobe were made: the superior frontal measurement was taken from the anterior tip of the frontal lobe to the superior limit of the central sulcus and the inferior frontal measurement was taken from the anterior tip of the frontal lobe to the point where the central sulcus joined, or would join the lateral sulcus if projected.

The thinnest part of the body of the corpus callosum in sagittal section was measured in millimetres. This point was located anterior to the splenium. The length of the thinned part varied from 0.5 to $1.5 \mathrm{~cm}$.

A block from a sagittal section of each thinned corpus 
callosum was prepared in paraffin, and sections cut at $5 \mu$ were stained by the haematoxylin and eosin, haematoxylin-van Gieson, Spielmeyer, Glees-Marsland, and Mallory's P.T.A.H. methods. Routine blocks were taken from the brain and mounted in celloidin; sections were cut and stained by the luxol fast blue with Nissl and P.T.A.H. methods.

Counts were made on silver-stained nerve fibres of $2.5 \mu$ in diameter, as seen in cross-section, and magnified 1,250 times onto the projection attachment of a Zeiss microscope. At least 30 fields were counted at random in each case and the number of fibres per sq. mm. calculated. Nerve fibres were counted instead of myelin sheaths to obviate errors arising from ballooning of the myelin which was present in some callosa. Fibres in the $2.5 \mu$ range were comfortable to see and therefore easy to count. A field of $7.0 \mathrm{~cm}$. square was drawn on the projection attachment of the microscope. Fibres overriding the upper and left-hand boundaries of the square were ignored, but those on the lower and right-hand boundaries were included in the counts.

Tissues from 11 brains of people who had not suffered from mental retardation were similarly measured and treated as control material.

Both hemispheres were measured in 14 brains and the mean values taken; measurements were confined to one hemisphere in five brains.

Cortical thickness at the crowns of gyri was measured at six sites according to the definitions of von Economo (1929). Measurements were made on fixed but un-

TABLE I

HEMISPHERICAL MEASUREMENTS, POSTERIOR CALlOSAL THICKNESS, AND POSTERIOR CALlOSAL FIBRE COUNTS IN EIGHT MENTALLY DEFECTIVE PATIENTS WITH POSTERIOR CALLOSAL THINNING

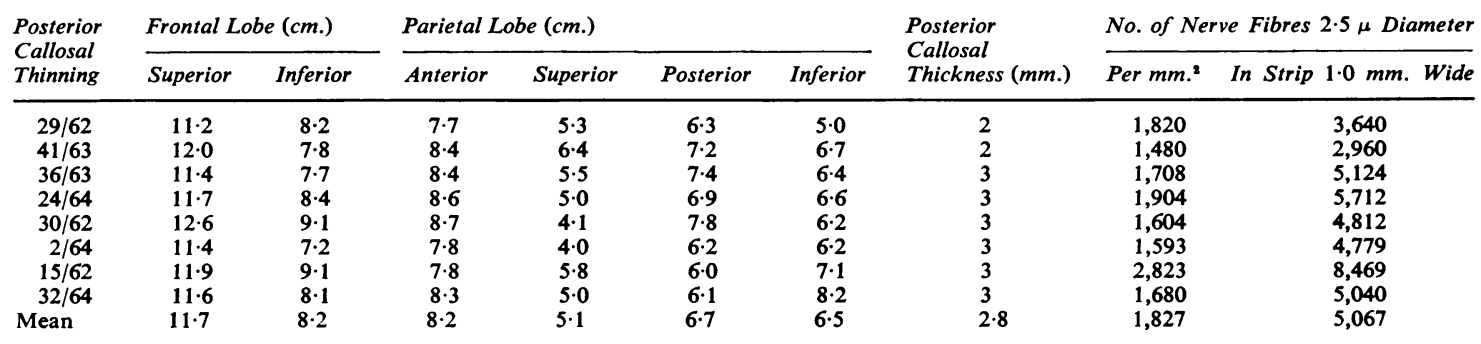

TABLE II

HEMISPHERICAL MEASUREMENTS, POSTERIOR CALLOSAL THICKNESS, AND POSTERIOR CALLOSAL FIBRE COUNTS IN 11 MENTALLY NORMAL CONTROLS

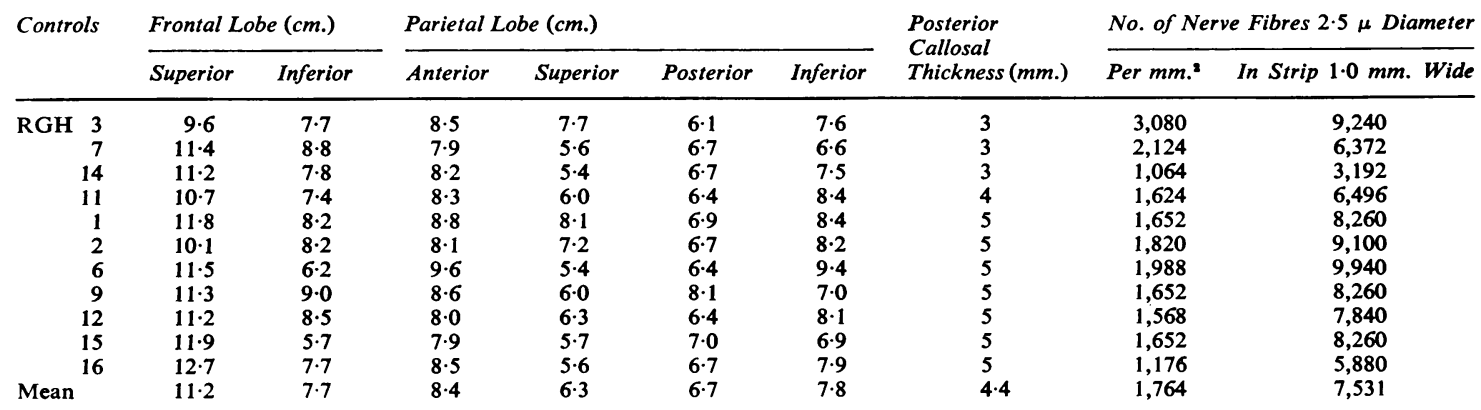

TABLE III

MEAN CORTICAL THICKNESS OF EIGHT CASES WITH POSTERIOR CALLOSAL THINNING COMPARED WITH THE FIGURES FOR 11 CONTROLS AND THOSE OF VON ECONOMO (1929)

\begin{tabular}{|c|c|c|c|c|c|}
\hline Motor Cortex & $\begin{array}{l}\text { Area of Gyrus } \\
\text { Rectus and } \\
\text { Orbital Gyri }\end{array}$ & $\begin{array}{l}\text { Superior Parietal } \\
\text { Area }\end{array}$ & $\begin{array}{l}\text { Area of Angular } \\
\text { Gyrus }\end{array}$ & $\begin{array}{l}\text { Convex Surface of } \\
\text { Occipital Lobe }\end{array}$ & $\begin{array}{l}\text { Medial and In- } \\
\text { ferior Temporal } \\
\text { Area }\end{array}$ \\
\hline
\end{tabular}

\begin{tabular}{llllll}
\hline Eight cases with & & & $3 \cdot 42$ & $3 \cdot 87$ \\
posterior callosal thinning & $3 \cdot 54$ & $3 \cdot 18$ & $3 \cdot 19$ & $3 \cdot 49$ & $2 \cdot 51$ \\
11 controls & $3 \cdot 59$ & $3 \cdot 14$ & $3 \cdot 06$ & $3 \cdot 49$ \\
von Economo & $3 \cdot 5-4 \cdot 5$ & $2 \cdot 0-2 \cdot 4$ & $2 \cdot 8-3 \cdot 0$ & $3 \cdot 0-3 \cdot 4$ & $2 \cdot 3-2 \cdot 6$
\end{tabular}


mounted tissue using a pair of dividers and a steel rule. There were 160 measurements on the eight observed and 218 on the 11 control brains.

\section{RESULTS}

The measurements for the dimensions of the parietal lobe, posterior callosal thickness, and number of fibres per square millimetre of corpus callosum are set out in Tables I and II. Measurements on cortical thickness are set out in Table III.

There was no significant difference between the superior and inferior frontal lengths of the two groups of brains.

In the eight brains showing thinning of the posterior callosal segment the superior frontal length, in each case, was matched with a similar frontal length from a control patient. Pairing observed with control material in this way the lengths of the superior parietal lobe measurements of the two groups were then compared. According to Wilcoxon's method for matched-pairs signed-ranks (Siegel, 1956), there was a significant smallness, at the 0.05 level, of the superior parietal lobe measurements in the brains of the patients. A similar method was applied to the inferior parietal lobe measurements, only in this case the matching measurements were the inferior frontal lobe lengths of the two groups. There was a significant difference beyond the 0.05 level in the size of the inferior parietal measurements of the two groups. Similarly, the anterior parietal lobe measurements were compared with the posterior lobe measurements but no significant difference was demonstrated.

Critchley (1953) states that the parietal cortex constitutes about one fifth of the total cortical area and that there is twice as much buried cortex as exposed. Three brains with small parietal measurements had ventricular dilatation compared with one of the control group. Ventricular dilatation was compensatory and chiefly located under the parietal lobe, thus encroaching on the space which should have been occupied by the buried parts of the cortex. Ventricular dilatation was thus an added indication of the smallness of the parietal lobes.

The density of fibre counts per square millimetre in the two groups of patients is also indicated in Tables I and II. A $t$ test applied to the means demonstrated that there was no significant difference between controls and observed material. The density figure was multiplied by the thickness of the corpus callosum and Wilcoxon's matched-pair signed-ranks test was then applied to the fibre counts. In the posterior callosal group there was a reduced number of fibres in the thinned part, although the density of fibres per square millimetre was the same as in the control group. There was a significant reduction of nerve fibres of $2.5 \mu$ calibre in the posterior callosal group compared with the controls, that is to say, beyond the 0.05 level of significance.

Bailey and Von Bonin (1951) estimated the total callosal fibre count to be about $10^{6}$. They assumed that the fibre diameter, presumably of myelinated fibres, was $5 \mu$, but this is not so. There is considerable variation in fibre size, as Tomasch found in the human corpus callosum and Luttenberg (1963) demonstrated in the callosa of cats, dogs, rabbits, and rats. According to Tomasch, the posterior part of the body is richest in the larger fibres but even so fibres of $5 \mu$ are rare.

The widths of the parietal cortex of the eight observed brains in Table III neither differed significantly from those of the control brains nor from the figures of von Economo (1929). Other cortical areas likewise appeared not to differ from the control material. The cytoarchitectonics of the isocortex in all areas of observed brains appeared normal on both casual inspection and measurement of laminal widths. Since the density of fibres constituting the thinned part of the callosal bodies was within normal limits, it seems reasonable to expect that cortical cell density should also be within normal limits. Total cell quantity would be reduced because the brain mass of the parietal lobe was reduced.

Microscopically, the corpora callosa showed good myelination and absence of gliosis and infiltration with abnormal cells. There was no break in the continuity of the indusium griseum and the striae longitudinales. In sections which included the body of the fornix this structure looked well myelinated and normal.

\section{DISCUSSION}

Ashby and Stewart (1934) set out to try and show that mental age could be associated with a small corpus callosum in a population of mental defectives. They reasoned that in such people, in whom the brain is often small and possessing fewer cells than normal, it could be expected that the corpora callosa would also be small. They did not take into account local abnormalities of the callosa. They measured the area of the corpus callosum and found that the area had no direct connexion with mental age, but that the apparent connexion was due to the fact that callosal size tended to vary with body weight and brain weight. Both these latter tended to vary with the mental age and hence provided a connexion between the corpus callosum and mental age.

Normal intelligence can occur with complete absence of the corpus callosum (Norman, 1958; Gyepes and Gannon, 1963). Since the fibres con- 
stituting the commissure have their cells of origin in the hemispheres, this presupposes that the isocortex must be healthy for normal intelligence to occur. According to the evidence presented here, there was a quantitative deficit of cortical tissue in the parietal lobes which was associated in eight patients with thinning of the posterior part of the callosal body. This fact would be greatly substantiated if it could be shown that there was a significant relationship between posterior callosal thickness and parietal lobe size. To do this it was possible to measure 30 brains with a range of posterior callosal thickness from 0.2 to $0.5 \mathrm{~cm}$. (mean $=0.38 \mathrm{~cm}$.) and to cut out a slab of hemisphere representing the parietal lobe from the landmarks indicated earlier. Parietal lobe weights ranged from 118 to $290 \mathrm{~g}$. $($ mean $=180 \cdot 2 \mathrm{~g}$.). A correlation $(r)$ was found to be $0 \cdot 56$, thus revealing a substantial and significant relationship between parietal lobe size and thickness of the posterior part of the body of the corpus callosum. This being so it is suggested that the absence of gliosis in the parietal lobes of the eight observed cases was evidence of cortical hypogenesis which had resulted in a reduction of the number of fibres traversing the posterior callosal body from one hemisphere to the other.

The 'clumsy child' syndrome is purported to have parietal dysfunction as the basis for its clinical features. Walton, Ellis, and Court (1962) described apraxic and agnostic features of the condition and emphasized that it and similar disorders can occur as isolated disabilities without other signs of neurological disturbance. Illingworth (1963) described these children as having a normal gait with minimal neurological signs but possessing clumsy movements, bad writing, a tendency to break glassware, and having a poor performance in physical training and dancing. Mental retardation has not featured in the cases reported; rather the contrary, so that it is important not to ignore clumsy children and regard them as retarded because of their handicap. Nevertheless, as this syndrome becomes more widely recognized, it is likely that niental deficiency will feature in the condition just as it does in cerebral palsy. The syndrome is newly recognized but doubtless it has been present for a long time, and many children with the condition will have found their way into mental deficiency hospitals where many patients show inadequately described clumsy actions with normal neurological signs. Difficulty in performance tests, especially with picture completion, block designs, and mazes, are important clues. Two of the patients in this series were known to have had such difficulties in adulthood, 30 years before their deaths. The 'clumsy child' syndrome occurred 27 times out of a total of 500 children with cerebral palsy in Illingworth's material; by comparison, over the period of time that it took to collect the eight cases here reported, 14 cases with cerebral palsy had come to necropsy.

The evidence suggests that there is a need to explore parietal lobe function in mentally handicapped people without motor disability. Ritchie Russell (1961) comments that when motor functions have never developed properly in cerebral palsied children, a crude anatomical diagnosis of parietal lobe dysfunction may be impossible by the methods adopted in adults. Likewise, in congenital athetosis the basal ganglia pathology will render the development of normal parietal lobe patterns impossible and their mechanisms will develop in hopeless confusion. It may well be that the customary clinical methods of approach to parietal lobe abnormalities, such as two-point, weight, and texture discrimination, may be too insensitive in patients with congenital abnormalities localized to the parietal lobes. New techniques may be required to study the problem further during life.

\section{SUMMARY}

Anatomical and statistical evidence is given on eight mentally retarded patients to show that there may exist, in this field of medicine, a condition consisting of specific smallness of the parietal lobes associated with narrowness of the posterior part of the callosal body. The cause is obscure but histological evidence suggests that hypogenesis is present.

I am grateful to Drs. N. O'Connor and P. Venables for helpful advice in the construction of this paper. I wish to thank Mr. A. Rundle for statistical advice and Mr. D. S. High and Miss Susan Willard who helped with recording information and preparing histological material.

\section{REFERENCES}

Ashby, W. R., and Stewart, R. M. (1934). The brain of the mental defective: a study of morphology in its relation to intelligence. Part II. The corpus callosum in its relation to intelligence. J. Neurol. Psychopath., 14, 217-226.

Bailey, P., and Von Bonin, G. (1951). The Isocortex of Man. University of Illinois Press, Urbana.

Critchley, M. (1953). The Parietal Lobes. Arnold, London.

Economo, C. von (1929). The Cytoarchitectonics of the Human Cerebral Cortex, translated by S. Parker. Oxford University Press, London.

Ettlinger, G., and Morton, H. B. (1963). Callosal section: its effect on performance of a bimanual skill. Science, 139, 485-486.

Gray, H. (1958). Gray's Anatomy, 32nd ed., edited by T. B. Johnston, D. V. Davies, and F. Davies, p. 1026. Longmans, Green, London.

Gyepes, M. T., and Gannon, W. E. (1963). Agenesis of the corpus callosum. N.Y. St. J. Med., 63, 1385-1387.

Illingworth, R. S. (1963). The clumsy child. In Minimal Cerebral Dysfunction. Little Club Clinics in Developmental Medicine No. 10, pp. 26-27. Medical Advisory Committee of the National Spastics Society, London. 
Luttenberg, J. (1963). Quantity and distribution of fibers according to thickness in the corpus callosum of cats, dogs, rabbits and rats. Čs. Morfol., 11, 291-300

McRae, D. L., and Castorina, G. (1963). Variations in corpus callosum, septum pellucidum and fornix, and their effect on the encephalogram and cerebral angiogram. Acta radiol. Diagn. (Stockh.), 1, 872-880.

Myers, R. E. (1959). Localization of function in the corpus callosum, Visual gnostic transfer. Arch. Neurol. (Chic.), 1, 74-77.

Norman, R. M. (1958). Microencephaly. In Neuropathology, by Greenfield, J. G. et al., p. 321. Arnold, London.
Riley, H. A. (1960). An Atlas of the Basal Ganglia, Brain Stem and Spinal Cord, p. 547. Hafner, New York.

Russell, W. Ritchie (1961). The parietal lobes. In Child Neurology and Cerebral Palsy. Little Club Clinics in Developmental Medicine No. 2, pp. 110-114. Medical Advisory Committee of the National Spastics Society, London.

Siegel, S. (1956). Nonparametric Statistics for the Behavioral Sciences, pp. 75-83. McGraw-Hill, New York.

Tomasch, J. (1954). Size, distribution, and number of fibres in the human corpus callosum. Anat. Rec., 119, 119-135.

Walton, J. N., Ellis, E., and Court, S. D. M. (1962). Clumsy children: developmental apraxia and agnosia. Brain, 85, 603-612. 